\title{
Radiation Hardening of LED Luminaires for Accelerator Tunnels
}

\author{
J. D. Devine, and A. Floriduz \\ CERN, Geneva, Switzerland
}

\begin{abstract}
This paper summarises progress made towards the radiation hardening of LED emergency luminaires for evacuation and emergency response within the underground areas of the CERN accelerator complex. The objective has been to radiation harden existing Commercial Off-The-Shelf (COTS) emergency luminaires to maximise lighting performance, without compromising IEC 605982-22 compliance. A systems level approach has been adopted, leading to the development of a diode bridge based AC/DC power converter. Modified COTS luminaires including this converter design have been irradiated (to $100 \mathrm{kGy}$ TID using a Cobalt-60 source), with results of a subsequent photometric analysis presented. Following encouraging tests results, a reference design for the power converter has been released under the CERN Open Hardware License to encourage manufacturer adoption. The paper concludes with areas of interest for future research in further improving the radiation hardness of LED emergency lighting for accelerators with detailed studies at the component level for high power white LED devices and associated optical components.
\end{abstract}

\section{Keywords}

Radiation resistant power supply; emergency lighting; particle accelerators.

\section{Introduction}

CERN has around $45 \mathrm{~km}$ of underground tunnels containing particle accelerators, beam transfer lines and access tunnels at depths of up to $100 \mathrm{~m}$ below the surface [1]. During accelerator shutdown periods extensive access is required for human operatives performing maintenance and upgrade activities. A robust emergency lighting system, comprising in excess of 3000 luminaires, exists to ensure safe evacuation from underground areas in the event of an emergency. Currently emergency lighting is provided by legacy lighting systems dating from the original underground accelerator installations (Super Proton Synchrotron and Large Electron Positron Collider) which comprise a mixture of low-pressure sodium and incandescent luminaires. These are now increasingly difficult to maintain due to regulations applicable to lighting systems which limit the supply of replacement lamps, creating the need for the development of a replacement system based on current lighting technology and radiation resistant properties.

\subsection{Emergency lighting systems}

Emergency lighting systems in tunnel accelerators are intended to provide a minimum level of illumination for escape routes, in case of a loss of power to normal luminaires. The purpose of emergency lights is to allow people working in underground areas to escape safely from the tunnels and to facilitate the intervention of emergency services if required. At CERN, emergency luminaires are supplied from rechargeable Nickle Metal Hydroxide (NiMh) batteries via 48 V DC to $230 \mathrm{~V}$ AC inverters. Luminaires are supplied through fire rated cables, with each underground area typically being served by two separate electrical circuits to provide redundancy. In most areas of the Large Hadron Collider (LHC) tunnel, the emergency lighting system makes use of low-pressure sodium discharge lamps retained from the era of the LEP accelerator. Sodium discharge lamps with wire wound inductive ballasts have proved to be highly reliable and radiation resistant throughout the radiation environments created by both the LEP and the LHC [2], as they are intrinsically highly tolerant to radiation effects. 


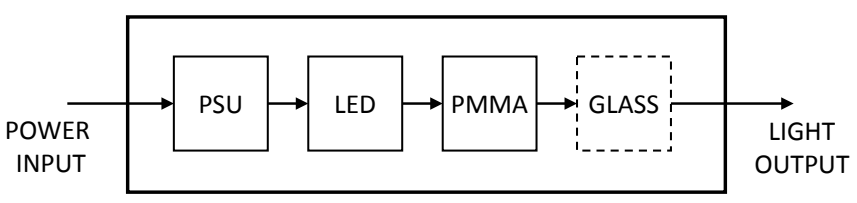

Fig. 1: System model of an LED emergency luminaire.

In recent years, Light-Emitting Diodes (LED) technology has become an attractive alternative to traditional incandescent, fluorescent and discharge lamps, not only for the general illumination market but also in the field of emergency lighting, thanks to their compact dimensions, instant response and high luminous efficacy. A major role in this transition has been played by national and international regulations, such as the EU directive no. 245/2009, which has led to a ban on certain types of inefficient metal halide, mercury and high-pressure sodium lamps. As a combined consequence of legislative pressure and technological progress, the expansion of the LED market appears inevitable while high intensity discharge lamps, including low-pressure sodium lights, are losing market share and ultimately becoming obsolete [3]. For this reason, a new generation of LED emergency luminaires is being developed for use in CERN underground facilities.

\subsection{Radiation environment}

The LHC radiation environment is characterised in [2], [4] and [5]. Since the emergency luminaires will eventually be installed on the walls of all underground areas (tunnels and caverns) of the CERN accelerator complex, they must be radiation hardened to an appropriate level in order to prevent premature failure. Working within the context of the As Low As Reasonably Achievable (ALARA) principle, the system must be designed to maximise operational lifetime, in order to prevent interventions related to luminaire breakdown and replacement. For this reason, the desired lifetime of emergency lighting luminaires is a minimum of 5 years.

The latest values (2015) of yearly High Energy Hadrons (HEH) fluence (i.e. fluence of all hadrons with an energy greater than $20 \mathrm{MeV}$ ), $1 \mathrm{MeV}$ equivalent neutron (neq) fluence and Total Integrated Dose (TID) in the LHC tunnel and its injectors are presented in [4]; in addition, this report illustrates that TID values on the tunnel walls are approximately one order of magnitude smaller than close to the corresponding beam lines, as evidenced by from both direct TID measurements and Monte Carlo simulations. Therefore, a suitable target dose for the emergency luminaires under development can be set to $100 \mathrm{kGy}$, since this value exceeds the expected TID relative to 5 years irradiation in most of the CERN accelerator complex, meeting the requirement of the desired lifetime.

In underground areas, an LED emergency lighting system may also be interlocked to activate only during machine stops (i.e. no beam condition), since no access to these areas is possible for human operators during accelerator runs ${ }_{1}^{1}$ Hence, LED emergency luminaires in CERN tunnels and caverns will also be studied when not powered, at ambient temperature (for reference, typical LHC tunnel temperature during physics runs is within the range $17 \pm 3^{\circ} \mathrm{C}$ ).

\subsection{LED luminaires}

The block diagram model of a COTS LED emergency luminaire is depicted in Fig. 1. The system comprises a number of components, including a Power Supply Unit (PSU), which converts the input

\footnotetext{
${ }^{1}$ Due to the long warm-up time of low-pressure sodium lamps, the present emergency luminaires in the CERN accelerator complex are always energised in order to avoid conflict with EN 1838 requirements for the rapid activation of emergency lighting systems. Therefore, adoption of LED lighting provides increased flexibility for energy savings thanks to potential for reduced operational time.
} 
supply voltage (typically $230 \mathrm{~V} 50 \mathrm{~Hz}$ AC) to the DC value required by the LEDs supplied. SwitchMode Power Supply (SMPS) topologies, such as buck, boost and flyback converters, are commonly used to supply LEDs [6] in COTS luminaires. However, these PSUs are not designed to be radiation hard and when tested show very poor performance, causing almost immediate catastrophic failure of LED luminaires when subjected to a typical accelerator radiation environment [7]. The reliability required for their use in accelerator environments (see, for example, [8] for a review of radiation effects on power converters), can therefore not be guaranteed. Each luminaire may contain one or more high power LED light sources, each with a lumen output of approximately $100 \mathrm{~lm}$ or greater. The effect of radiation on LED light output has been studied extensively for optical power levels up to $100 \mathrm{~mW}$ [9], [10], [11] however little published research exists for high power LEDs up to $1 \mathrm{~W}$ and beyond. The individual LED is generally equipped with a plastic lens to improve the light output distribution (see Fig. 1); the lens is usually made of PolyMethyl MethAcrylate (PMMA) plastic selected for high light transmission, a property which degrades when exposed to radiation [12]. Depending upon the luminaire design, the LED may also be contained in an IP6X housing protected with glass windows to allow light transmission (see Fig. 1). Borosilicate retains its optical transmission properties relatively well when irradiated [13] and has been specified for installations following the tests described in this paper. However, the overall light output of the system may be further improved by careful selection of quartz or high purity fused silica materials [14] in the future.

Having developed a simple system level model for the LED luminaires, the failure modes of each component and the corresponding impact on the system performance can be demonstrated (see Table 11. Early functional testing on a range of COTS products rapidly indicated that first stage of radiation hardening would be to prevent the catastrophic failure mode of the PSU due to the inclusion of sensitive SMPS. Following this insight, CERN has worked with two luminaire vendors to modify their standard products into radiation hardened versions. The luminaires contain modified PSUs, based on a diode bridge rectifier principle, providing significantly increased radiation hardness, and do not conflict with the requirements of IEC 60598-2-22.

Table 1: Radiation effects on luminaire components.

\begin{tabular}{ll}
\hline Component & Effects of radiation \\
\hline PSU & Catastrophic failure modes for SMPS \\
\hline LED & $\begin{array}{l}\text { Radiation damage (displacement) leading to reduced } \\
\text { flux }\end{array}$ \\
\hline PMMA (plastic & $\begin{array}{l}\text { Free radical formation leading to reduced light } \\
\text { transmission } \\
\text { lens compound) } \\
\text { Degraded mechanical properties }\end{array}$ \\
\hline Glass & $\begin{array}{l}\text { Colour centre formation leading to reduced light } \\
\text { transmission }\end{array}$ \\
\hline
\end{tabular}

\section{Design response}

\subsection{Preliminary irradiation tests}

Preliminary irradiation tests of two sets of COTS emergency lighting systems have been performed at CNRAD facility [15] at CERN. The goal was to analyse the response to radiation of COTS power supplies in order to identify a suitable basis for future design of a rad-tolerant PSU for LED lighting. 


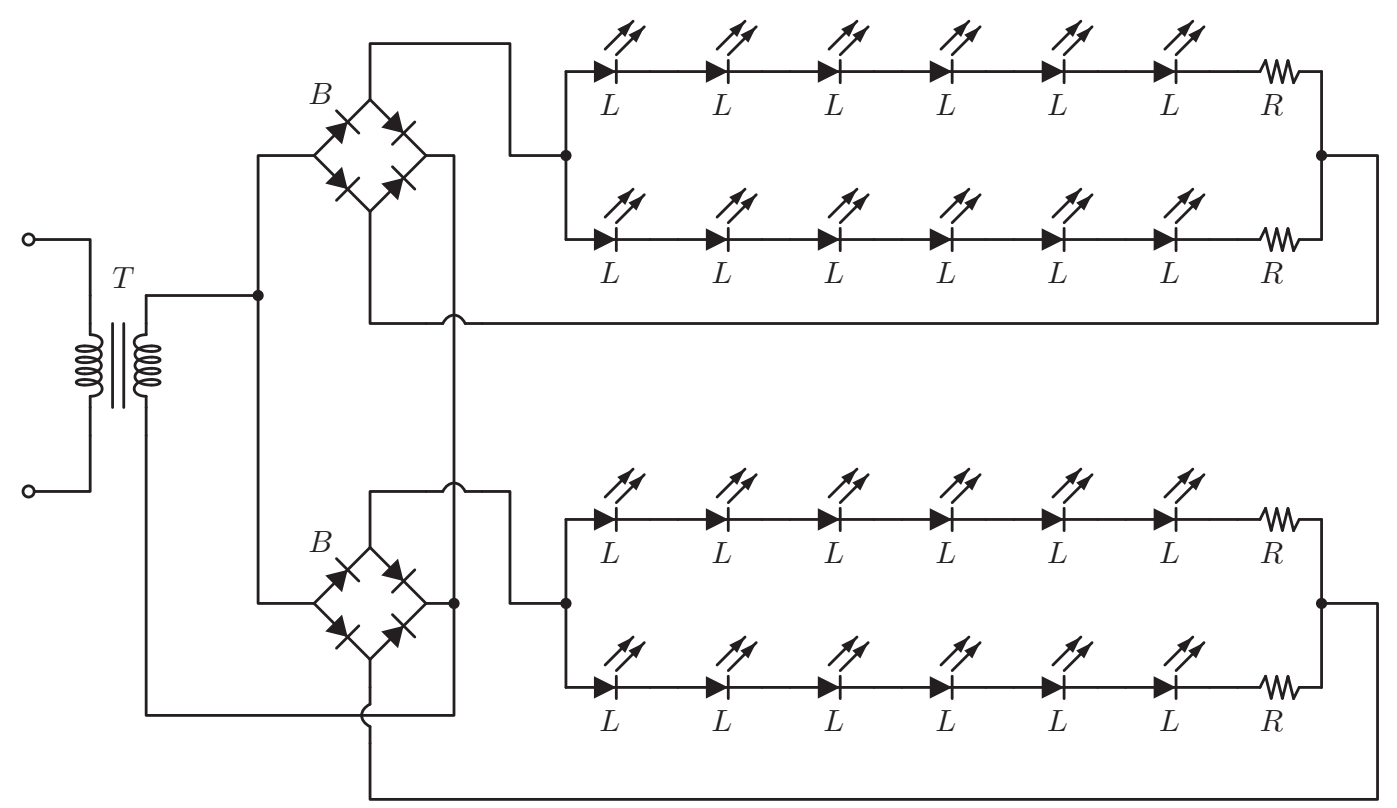

(a)

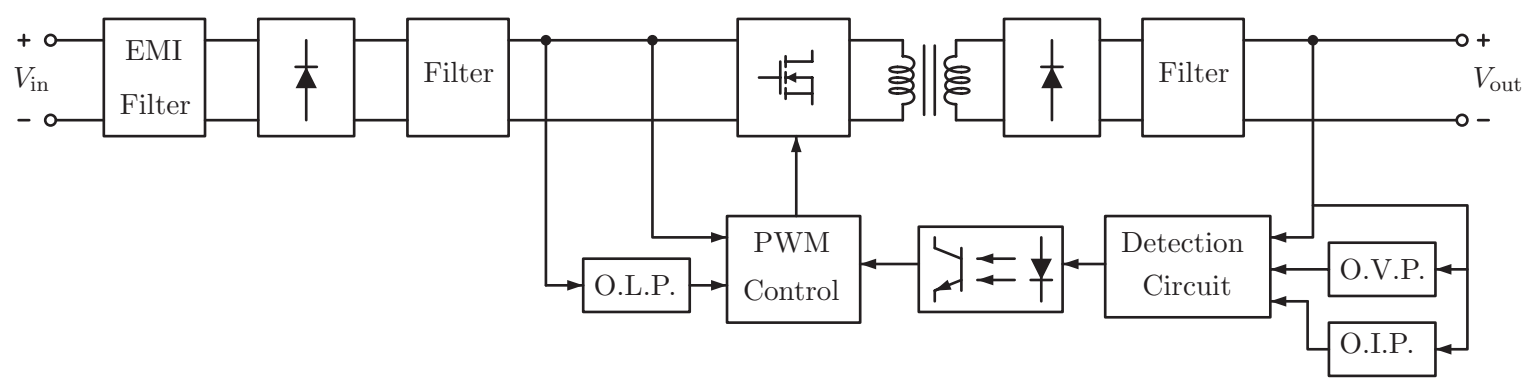

(b)

Fig. 2: (a) Circuit diagram of the power supply using diode bridge rectifier topology. (b) Block diagram of the SMPS used in COTS luminaires under test.

The first set of luminaires under test comprised three lamps with a simple power supply based on the principle of a transformer and a diode bridge rectifier, whose circuit diagram is represented in Fig. 2a. Each luminaire presents a step down transformer (denoted with $T$ on the circuit diagram) supplying two W08M diode bridge rectifiers (manufactured by MIC Electronics, and denoted with $B$ ), each one feeding two parallel strings of six series connected low power, low current $(<50 \mathrm{~mA})$ white LEDs, indicated as $L$. Each string is series connected to a $560 \Omega$ resistance in order to prevent thermal runaway of LEDs. The second batch comprised three luminaires using SMPS converters, whose block diagram is depicted in Fig. 2b. As can be seen, the AC input voltage is first rectified and filtered; an EMI filter is used to mitigate the injection of harmonics into the grid. Then, this stage is followed by a high frequency DC/DC converter composed of an inverter using MOSFET power switches, an high frequency transformer and an $\mathrm{AC} / \mathrm{DC}$ diode rectifier followed by a filter, to smooth the DC voltage. The power switches of the inverter are controlled via PWM modulation, at a switching frequency of $60 \mathrm{kHz}$. The control feedback loop is closed by the measurement/detection system, which sends backs to the control circuitry the DC output voltage, using opto-couplers. In order to prevent overloads on the input and output side, an overcurrent protection system (respectively denoted as O.L.P. and O.I.P. on the input and output side) is embedded 


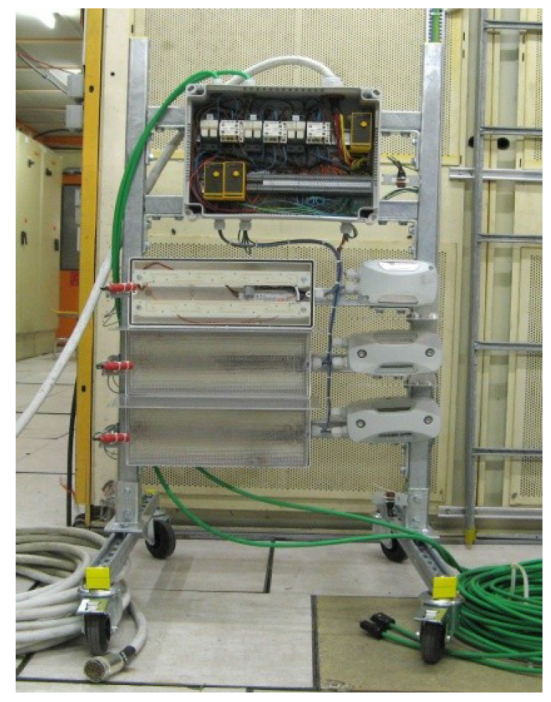

(a)

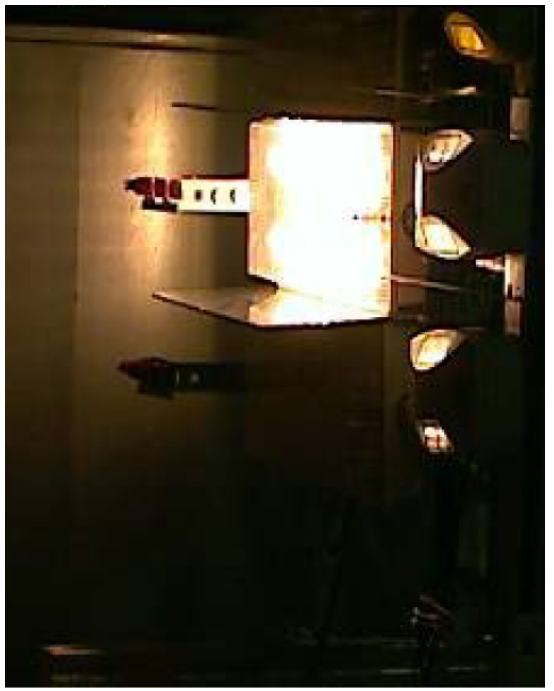

(b)

Fig. 3: (a) Layout of luminaires during preliminary irradiation tests at CNRAD (CERN); on the left, three luminaires using SMPS, on the right three luminaires with diode bridge rectifiers. (b) Picture from remote camera after 5 hours of irradiation; the three luminaires using diode bridges are on the right, luminaires with SMPS on the left.

into the control system; moreover, and Over Voltage Protection (O.V.P.) on the DC output side is also present.

The irradiation took place into four steps, with cumulative TID of 9, 47.9, 93.7 and 129.3 Gy. The four irradiation steps lasted respectively 230, 900, 1260 and 1095 hours, separated by intervals with no irradiation of 109, 75 and 105 hours. The irradiation conditions are summarized in Table 2. The six luminaires were installed on a test bench (illustrated in Fig. 3a), located in CNRAD test area, with a deported RadMon [16] positioned in the middle of the rack, at about $60 \mathrm{~cm}$ from ground, to measure precisely the radiation level of the devices under test. All luminaires were powered while irradiated (active test) and were monitored through a remote rad-hard camera.

Table 2: Irradiation condition of the COTS luminaires.

\begin{tabular}{lccccc}
\hline & Step 1 & Step 2 & Step 3 & Step 4 & Total \\
\hline TID (Gy) & 9 & 38.9 & 45.8 & 35.6 & 129.3 \\
$1 \mathrm{Mev}$ neq fluence $\left(10^{11} \cdot \mathrm{cm}^{-2}\right)$ & 0.7 & 3.0 & 3.6 & 2.7 & 10.0 \\
HEH fluence $\left(10^{11} \cdot \mathrm{cm}^{-2}\right)$ & 0.5 & 2.1 & 2.5 & 1.9 & 7.0 \\
Duration (h) & 230 & 900 & 1260 & 1095 & 3485 \\
Time after previous step (h) & $/$ & 109 & 75 & 105 & $/$ \\
\hline
\end{tabular}

The three luminaires using SMPS units failed just after the start of the test, after 1 hour, 4 hours and 18 hours of irradiation, corresponding to TID values of less than $0.1 \mathrm{~Gy}, 0.1 \mathrm{~Gy}$ and 0.4 Gy respectively. These results are summarized in Table 3 . Figure $3 \mathrm{~b}$ shows the test bench from the remote camera after 5 hours of irradiation, with two of the luminaires using SMPS already failed. The failure of SMPS luminaires can be ascribed to displacement damage effects on the power switches of the high frequency DC/DC converter, on the PWM control circuitry and on opto-couplers.

Luminaires using power supplies with diode bridge rectifiers succeeded in completing the irradi- 
Table 3: Irradiation of luminaires with SMPS.

\begin{tabular}{lccc}
\hline Characteristics & Luminaire 1 & Luminaire 2 & Luminaire 3 \\
\hline Time before failure (h) & 1 & 4 & 18 \\
TID reached (Gy) & $<0.1$ & 0.1 & 0.4 \\
HEH fluence $\left(\mathrm{cm}^{-2}\right)$ & $<5.4 \cdot 10^{8}$ & $5.4 \cdot 10^{8}$ & $2.2 \cdot 10^{9}$ \\
$1 \mathrm{MeV}$ neq fluence $\left(\mathrm{cm}^{-2}\right)$ & $<7.3 \cdot 10^{8}$ & $7.3 \cdot 10^{8}$ & $2.9 \cdot 10^{9}$ \\
\hline
\end{tabular}

ation test, working for the full duration without showing any significant degradation in illuminance, as confirmed by visual inspections and luxmeter measurements performed after the end of the irradiation. The total dose reached was of $129 \mathrm{~Gy}$, at a HEH fluence of $7.0 \cdot 10^{11} \mathrm{~cm}^{-2}$ and $1 \mathrm{MeV}$ neq fluence of $1.0 \cdot 10^{12} \mathrm{~cm}^{-2}$.

The irradiation test identified the power supply as the most critical component in COTS emergency luminaires and confirmed that converters using diode bridge topology offer an higher reliability in radiation environment than SMPS. Following these preliminary results, a prototype of a rad-tolerant PSU using the bridge rectifier topology has been built; this converter includes a GBU8K diode bridge, samples of which have been previously tested for radiation hardness by the LHCb experiment [17], up to $1 \mathrm{MeV}$ neq fluence of $4.8 \cdot 10^{13} \mathrm{~cm}^{-2}$, corresponding to a TID of $3.3 \mathrm{kGy}$; GBU8K bridge rectifier makes use of glass passivated junctions. The circuit diagram of the prototype power supply is shown in Fig. 4a, it includes a 230:6 step-down transformer (denoted with $T_{\mathrm{p}}$ in Fig. 4a) and an electrolytic $220 \mu \mathrm{F}$ capacitor (denoted with $C_{\mathrm{p}}$ ). The power supply feeds a single Cree XR-E LED, indicated with $L_{\mathrm{p}}$, producing white light; Cree XR-E LED is in turn composed of a blue InGaN LED and yellow phosphors. A picture of an assembled prototype is shown in Fig. 4b 2 PSU prototypes have been tested in CNRAD facility, in a test position which allowed higher TID and fluences than the location of the previous test of COTS luminaires. Irradiation took place in four steps with cumulated TID of 160.2, 406.1, 760.1 and $1107.6 \mathrm{~Gy}$, with final cumulated HEH fluence of $1.1 \cdot 10^{13} \mathrm{~cm}^{-2}$ and cumulated $1 \mathrm{MeV}$ neq fluence of $7.7 \cdot 10^{12} \mathrm{~cm}^{-2}$. From a comparison with the values presented in [4], the TID reached during this irradiation test corresponds approximately to the dose accumulated on the LHC tunnel walls after 5 years exposure. All the PSUs were powered while irradiated (active test). Inspections were performed after the last irradiation step, and confirmed that all PSUs were still working. Following this encouraging result, the prototype has been chosen as the basis for a rad-tolerant PSU for LED lighting.

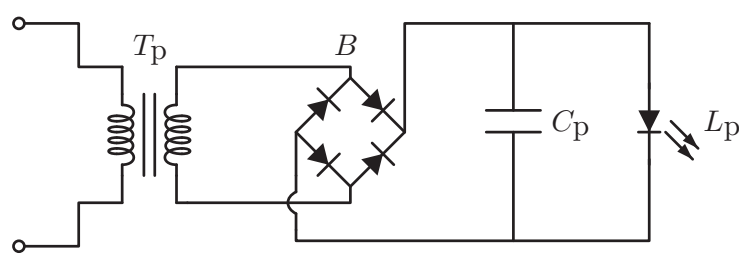

(a)

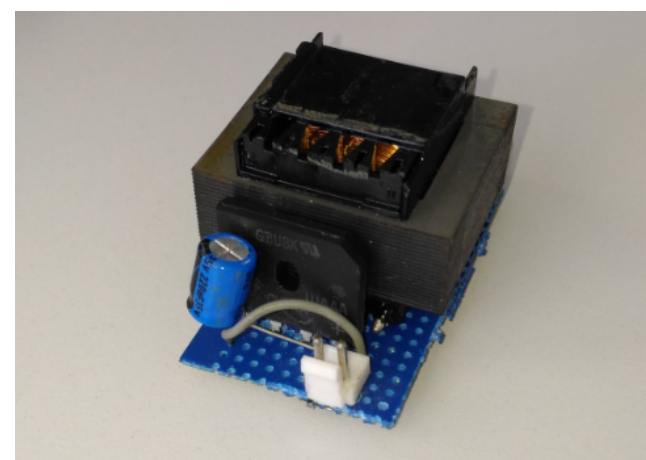

(b)

Fig. 4: (a) Circuit diagram of the prototype power supply using GBU8K diode bridge rectifier. (b) Picture of the prototype PSU assembled on a stripboard. 
Table 4: Irradiation condition of the prototype PSU.

\begin{tabular}{lccccc}
\hline & Step 1 & Step 2 & Step 3 & Step 4 & Total \\
\hline TID (Gy) & 160.2 & 245.9 & 354 & 347.5 & 1107.6 \\
1 Mev neq fluence $\left(10^{12} \cdot \mathrm{cm}^{-2}\right)$ & 1.6 & 2.4 & 3.5 & 3.4 & 11 \\
HEH fluence $\left(10^{12} \cdot \mathrm{cm}^{-2}\right)$ & 1.1 & 1.7 & 2.5 & 2.4 & 7.7 \\
\hline
\end{tabular}

\subsection{Power Supply Modifications}

Once a suitable power converter topology had been identified, work with luminaire vendors was commenced in order to incorporate the new power converter topology into standard products with optical characteristics suitable for emergency evacuation lighting within underground tunnels. A second vendor with an alternative luminaire design more suited to underground caverns and larger spaces was also approached. The power converter specification was issued to both vendors, which included the same bridge diode rectifier (GBU8K) used in the prototype PSU presented in Section 2.1. As a result of these initiatives, two types of radiation hardened emergency luminaire were produced for further radiation testing. The circuit diagrams of Vendor 1 and Vendor 2 power supplies are shown respectively in Fig. $5 \mathrm{a}$ and Fig. 5b. The values of the components are listed in Table 5 .

\subsection{Components under test}

The luminaires from Vendor 1 utilise three Cree XP-G LEDs as light sources, with a combination of PMMA lenses and glass windows. Vendor 2 uses a single Cree XR-E LED with a PMMA lens to direct the light output. Cree XR-E and XP-G LEDs produce white light; they are composed of blue LEDs (InGaN epitaxial layer on silicon substrate) with phosphors producing yellow light. To the best of our knowledge, no previous irradiation tests of Cree XR-E and XP-G LEDs have been reported. Both luminaires use the GBU8K diode manufactured by Vishay. Further components include surface mounted multi-layer ceramic capacitors and metal-film resistors.

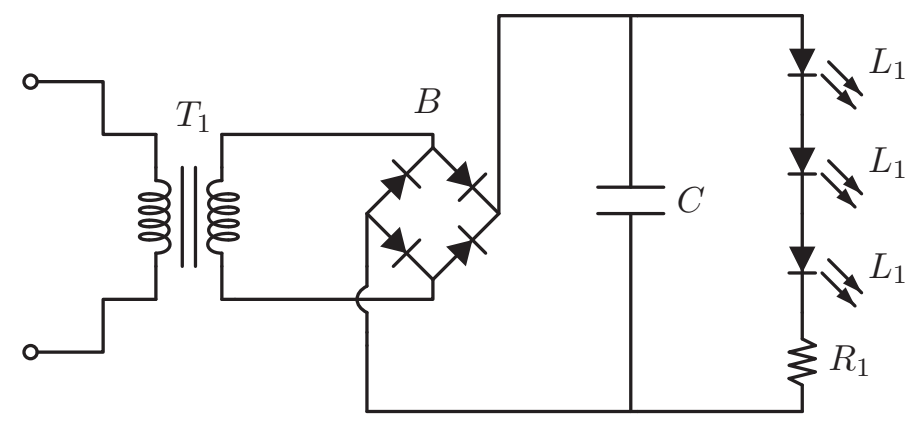

(a)

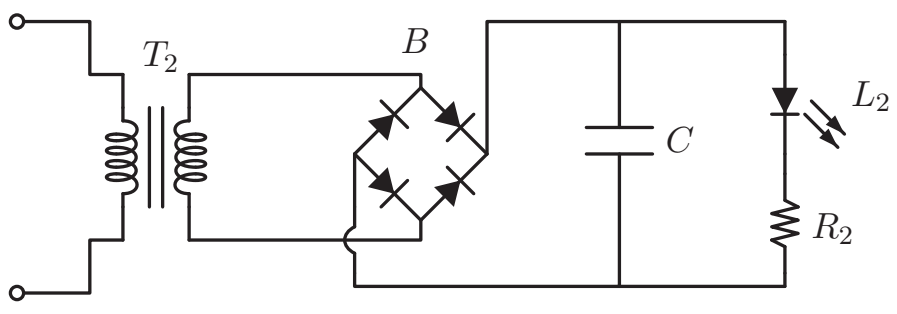

(b)

Fig. 5: (a) Circuit diagram of Vendor 1 power supply. (b) Circuit diagram of Vendor 2 power supply. 
Table 5: Electrical components of Vendor 1 and Vendor 2 power supplies.

\begin{tabular}{llll}
\hline Name & Quantity & Name & Quantity \\
\hline$T_{1}$ & 16 VA transformer, 230:14 & $C$ & $1 \mathrm{mF}$ ceramic capacitor \\
$T_{2}$ & 16 VA transformer, 230:7 & $L_{1}$ & Cree XR-E white LED \\
$R_{1}$ & $16 \Omega 5 \%$ resistor, 25 W & $L_{2}$ & Cree XP-G white LED \\
$R_{2}$ & $5 \Omega 5 \%$ resistor, 25 W & $B$ & GBU8K diode bridge rectifier \\
\hline
\end{tabular}

\section{Experimental results}

\subsection{Test methodology}

Gamma ray and neutron irradiation was performed on luminaires from both vendors. Gamma ray irradiation was conducted at the Fraunhofer Institute INS (Germany) to a TID of $100 \mathrm{kGy}$; two sample luminaires for each vendor were sent to Fraunhofer for test purposes. Neutron irradiation was performed at CEA in France on another set of samples, likewise composed of two luminaires from Vendor 1 and two luminaires from Vendor 2. Analysis of the neutron irradiated samples will be presented in a future work. In addition to irradiation tests, a trial installation using the proposed LED luminaires has recently been completed in part of the SPS accelerator complex (TDC2 and TCC2 tunnels and target caverns) with a very challenging radiation environment [18], with half of the luminaires permanently on and half interlocked to activate only when there is no beam present in the accelerator.

The gamma ray irradiation has been performed at the BGS low dose test facility at Fraunhofer, using a Cobalt-60 source at a dose rate of $720 \mathrm{~Gy}(\mathrm{Si}) / \mathrm{h}$, to a final dose value of $100 \mathrm{kGy}(\mathrm{Si})$. The luminaires were not powered during irradiation (passive test). As detailed in Section 1.2, in CERN tunnels LED luminaires may be powered off while irradiated; for this reason, passive irradiation tests are also representative of actual radiation effects in accelerator tunnel environment. The irradiation was conducted in five steps, with final dose per exposure of 4.1, 15.3, 34.2, 50.0 and $100.0 \mathrm{kGy}(\mathrm{Si})$. After each step (and within three hours after the completion of the exposure), preliminary electrical and optical measurements were taken to verify the continued functioning of the luminaire. For each step, this activity took less than two hours. The irradiation of the sample luminaires lasted overall 146.7 hours. The time interval between the end of a step and the beginning of the following one was within 5 and 20 hours. The salient data of the gamma ray irradiation test are summarized in Table 6 .

Table 6: Summary of gamma ray irradiation conditions.

\begin{tabular}{ll}
\hline Parameter & Value \\
\hline Irradiation facility & BGS low dose \\
Irradiation source & Co-60 gamma \\
Dose steps & $4.1,15.3,34.2,50.0,100.0 \mathrm{kGy}(\mathrm{Si})$ \\
Dose rate & $720 \mathrm{~Gy}(\mathrm{Si}) / \mathrm{h}$ \\
Time of irradiation & $146.7 \mathrm{~h}$ \\
Time between steps & $9,8,5,20$ hours \\
\hline
\end{tabular}




\subsection{Results from goniophotometer analysis}

Following the gamma irradiation exposure, the luminaires were sent for a Type C Moving Mirror goniophotometer analysis at TSI-LUX Ltd. in the UK. Electrical and photometric measurements have been performed and the results are collected in Table 7 .

Table 7: Summary of electrical and photometric measurements.

\begin{tabular}{lcc}
\hline Quantity & Vendor 1 & Vendor 2 \\
\hline Frequency & $50 \mathrm{~Hz}$ & $50 \mathrm{~Hz}$ \\
Voltage & $230.06 \mathrm{~V}$ & $230.04 \mathrm{~V}$ \\
Current & $0.031 \mathrm{~A}$ & $0.031 \mathrm{~A}$ \\
Power & $6.50 \mathrm{~W}$ & $6.20 \mathrm{~W}$ \\
Power factor & 0.924 & 0.879 \\
Apparent power & $7.04 \mathrm{VA}$ & $7.09 \mathrm{VA}$ \\
CRI (Ra) & 71 & 65 \\
Luminous flux pre-irradiation & $900 \mathrm{~lm}$ & $209 \mathrm{~lm}$ \\
Luminous flux post-irradiation & $177 \mathrm{~lm}$ & $55 \mathrm{~lm}$ \\
Variation in luminous flux & $-80.33 \%$ & $-73.68 \%$ \\
Luminous efficacy pre-irradiation & $128.57 \mathrm{~lm} / \mathrm{W}$ & $32.15 \mathrm{~lm} / \mathrm{W}$ \\
Luminous efficacy post-irradiation & $27.23 \mathrm{~lm} / \mathrm{W}$ & $8.87 \mathrm{~lm} / \mathrm{W}$ \\
Variation in luminous efficacy & $-78.82 \%$ & $-72.41 \%$ \\
\hline
\end{tabular}

\subsection{Analysis of results}

From a comparison of the luminous flux before and after irradiation, an overall reduction of $80.3 \%$ has been observed for Vendor 1 luminaires. This reduction appears to be predominantly due to the glass, which became dark just after the $4.1 \mathrm{kGy}$ exposure (see Fig. 6a), and the PMMA lenses of the LEDs, which turned yellow. Figure $6 \mathrm{~b}$ shows the luminaire switched on, emitting a yellowish light, after a dose of $50 \mathrm{kGy}$. Finally, Figures $7 \mathrm{a} 7 \mathrm{e}$ show Vendor 1 luminaires after every irradiation step. As for

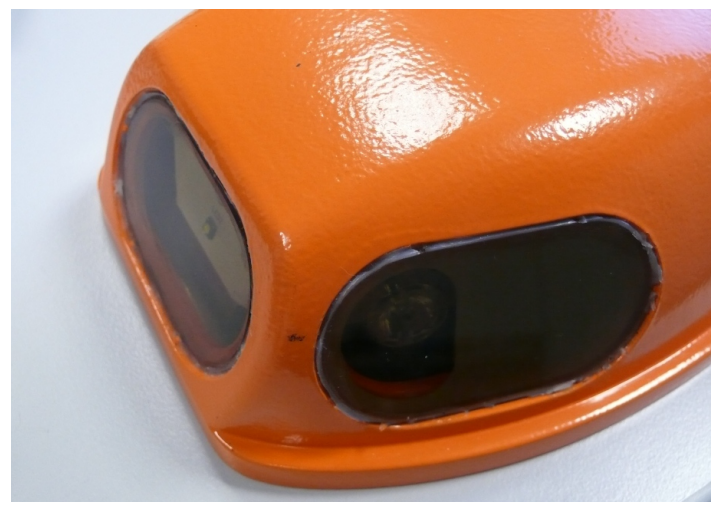

(a)

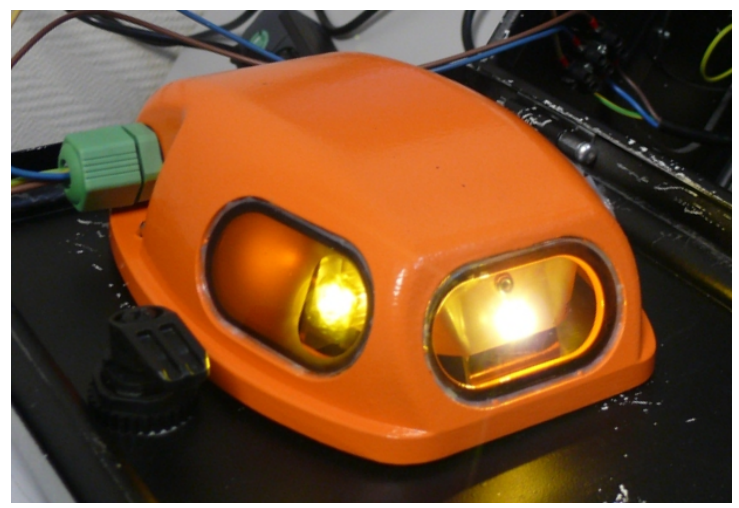

(b)

Fig. 6: (a) Detail of Vendor 1 luminaire glasses after $4.1 \mathrm{kGy}$ irradiation. (b) Vendor 1 luminaire on, after $50 \mathrm{kGy}$ irradiation. 
Vendor 2 product, the drop in the luminous flux is slightly lower than Vendor 1, thanks to the absence of the glass, and can be ascribed to the degradation in the PMMA which started to become yellow after a dose of $15 \mathrm{kGy}$. Figures $8 \mathrm{a}$ e illustrate Vendor 2 luminaires after every irradiation step. The variations in luminous efficacy are close to those in luminous flux for both products, meaning that no significant variation in input power (due to LEDs and diodes degradation) has been observed.

The data from the photometric measurement has been integrated into a DIALux model for a lighting simulation of a typical segment of the LHC tunnel. Fixing centres of the luminaires are designed to account for the reduction in luminous flux due to radiation. In the simulation, Vendor 1 luminaires are placed on the tunnel wall at fixing centres of $14 \mathrm{~m}$, while Vendor 2 luminaires are positioned on the ceiling of the tunnel at $10 \mathrm{~m}$ fixing centres. The simulation results of Vendor 1 product are summarized in Table 8 and a 3D rendering in false colour is shown in Fig. 9a. We recall that EN 1838 standard requires a minimum of $0.5 \mathrm{~lx}$ for anti-panic lighting and $1 \mathrm{~lx}$ for escape routes (at centre line). For this reason, the plastic and glass types for future luminaires will be carefully selected to improve optical transmission when irradiated. The same analysis has been performed for Vendor 2 luminaire, and results are shown in Table 8 and Fig. 9b. Figure $9 \mathrm{c}$ illustrates the natural visual impression of the tunnel segment using luminaires of both vendors after $100 \mathrm{kGy}$ irradiation.

Table 8: DIALux simulations of Vendor 1 and Vendor 2 luminaires in LHC tunnel.

\begin{tabular}{lccccc}
\hline \multirow{2}{*}{ Quantity } & \multicolumn{2}{c}{ Vendor 1} & \multicolumn{2}{c}{ Vendor 2} \\
& Before & After & Before & After \\
\hline Average over the whole surface & $9.78 \mathrm{~lx}$ & $2.01 \mathrm{~lx}$ & $3.46 \mathrm{~lx}$ & $1.60 \mathrm{~lx}$ \\
Maximum value over the whole surface & $17.0 \mathrm{~lx}$ & $9.45 \mathrm{~lx}$ & $6.01 \mathrm{~lx}$ & $2.78 \mathrm{~lx}$ \\
Minimum value along the escape route & $5.67 \mathrm{~lx}$ & $0.65 \mathrm{~lx}$ & $1.85 \mathrm{~lx}$ & $0.92 \mathrm{~lx}$ \\
Minimum value at center line along escape route & $7.48 \mathrm{~lx}$ & $1.22 \mathrm{~lx}$ & $2.02 \mathrm{~lx}$ & $1.02 \mathrm{~lx}$ \\
\hline
\end{tabular}

\section{Future developments}

The need for a new PSU as the first stage in radiation hardening COTS luminaires, together with impending obsolescence of the GBU8K rectifier, has spurred the production of a reference design, released under the CERN Open Hardware License [19]. Future tests up to $100 \mathrm{kGy}$ are planned for the new PSU in CHARM facility at CERN [20] using mixed field radiation produced from $24 \mathrm{GeV}$ protons, investigating also the effect of different load conditions. Dedicated irradiation tests for the power LEDs are scheduled at IRRAD facility at CERN [21], so as to identify the impact of displacement damage using $24 \mathrm{GeV}$ protons, under different bias conditions. Likewise, gamma ray irradiation tests for samples of optical components (PMMA lenses and borosilicate windows) are planned. Future studies will address the analysis of photometric data from the neutron irradiated sample luminaires, which will provide a stronger indication on the effect of displacement damage to the LEDs, and the consequent impact on overall system performance. For the purposes of this paper, the effects of annealing within the LED die have been ignored due to a significant delay between irradiation and photometric measurement, however the impact of this phenomena would also be an interesting subject for future study, within the context of the duty cycle for the luminaires and operational practices of particle accelerators.

\section{Conclusions}

In this paper, we presented progress towards radiation hardening of LED emergency luminaires for use in accelerators environments. After the identification of the PSU as the cause of early catastrophic failures in COTS luminaires, we described a simple AC/DC power supply for LED emergency luminaires, the 


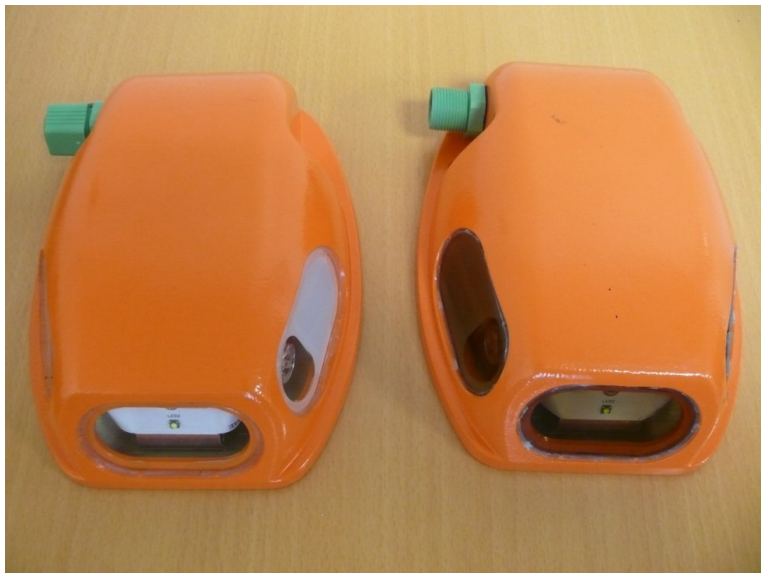

(a)

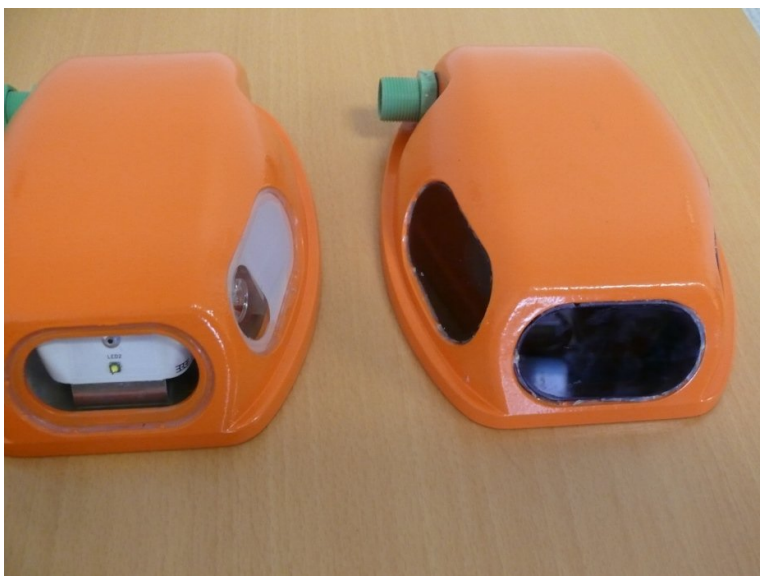

(c)

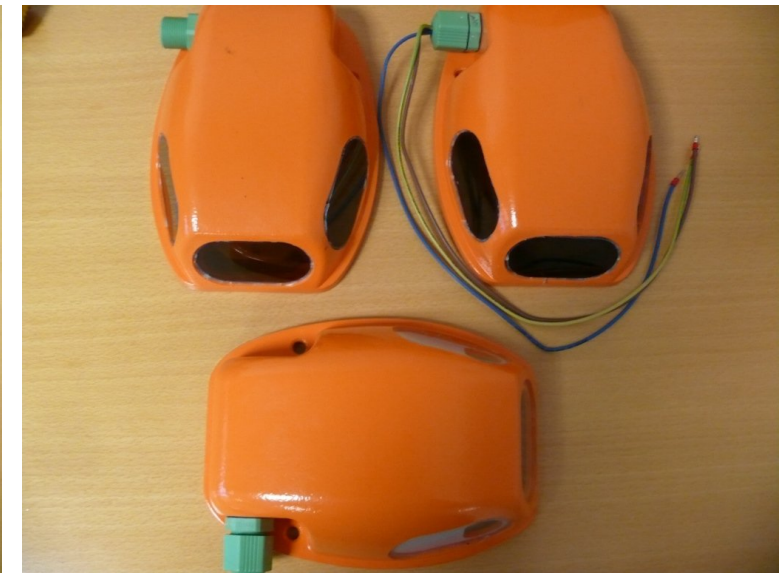

(b)

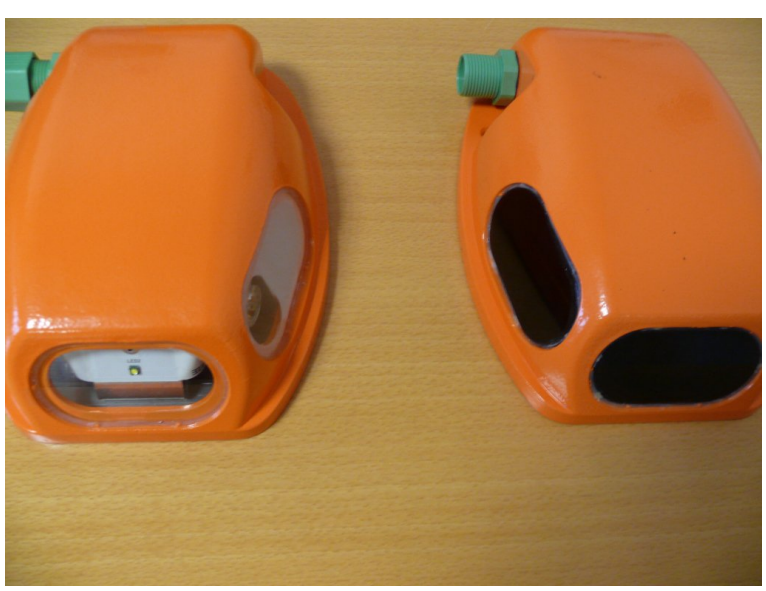

(d)

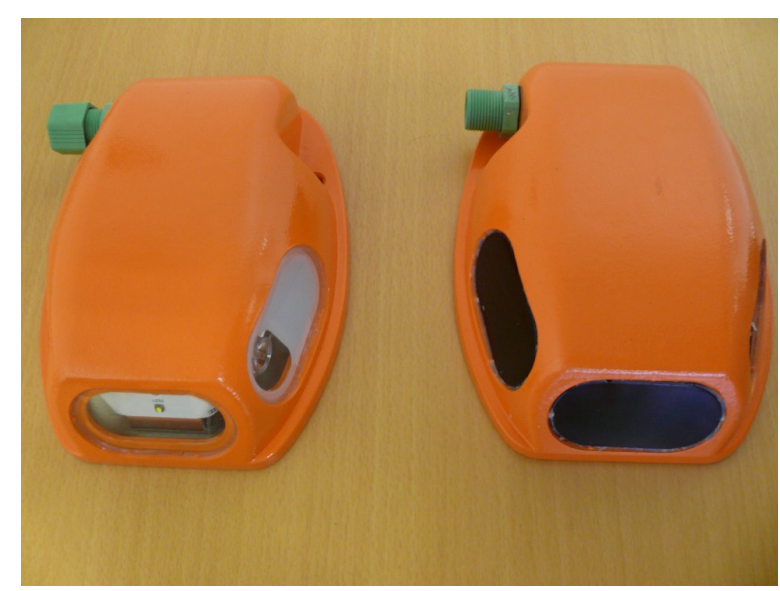

(e)

Fig. 7: Comparison between irradiated and non-irradiated Vendor 1 luminaires after exposure to: (a) $4.1 \mathrm{kGy}$, (b) $15.3 \mathrm{kGy}$, (c) $34.2 \mathrm{kGy}$, (d) $50 \mathrm{kGy}$, (e) $100 \mathrm{kGy}$. In Figure (b) both irradiated luminaires are shown. 


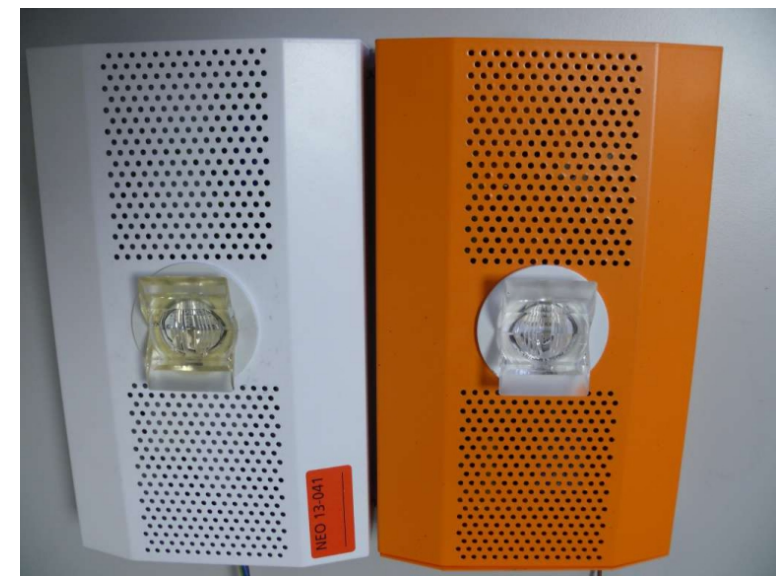

(a)

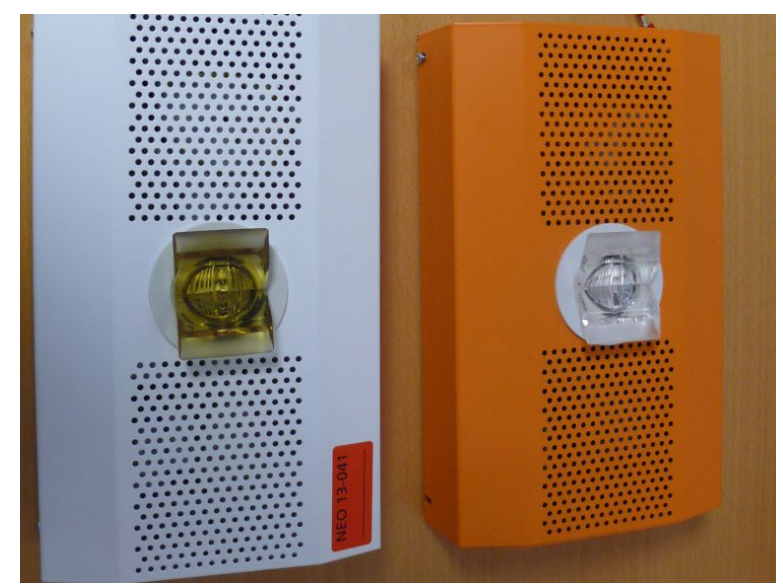

(c)

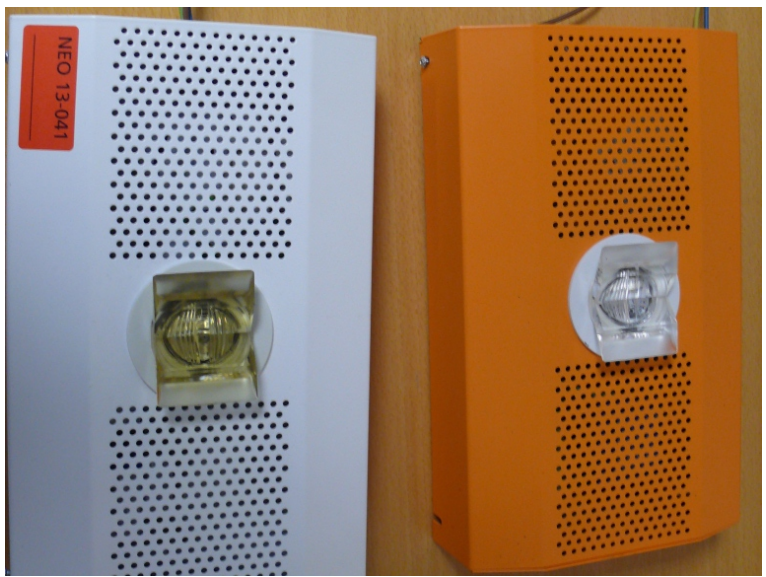

(b)

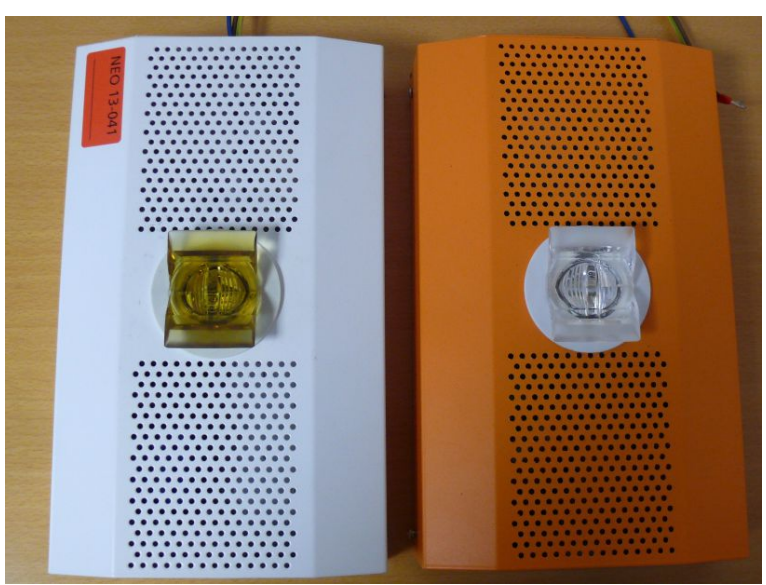

(d)

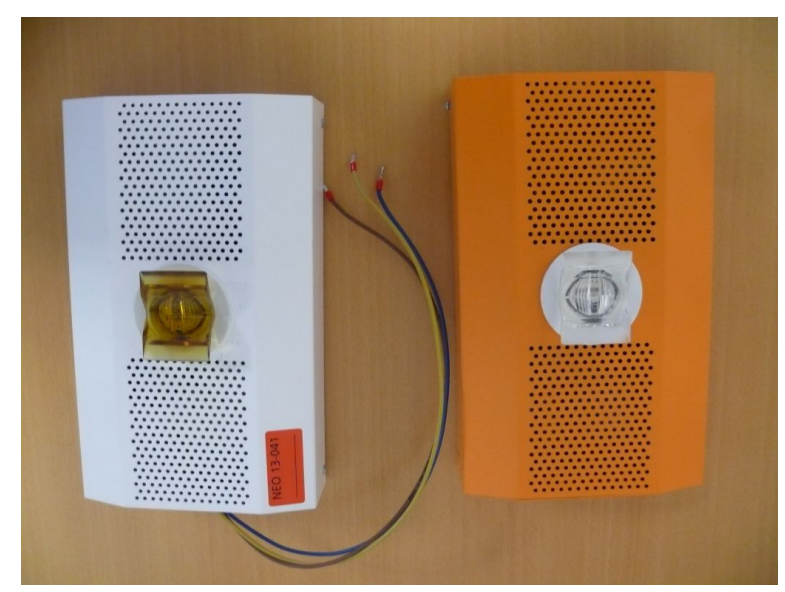

(e)

Fig. 8: Comparison between an irradiated (white) and non-irradiated (orange) Vendor 2 luminaire after exposure to: (a) $4.1 \mathrm{kGy}$, (b) $15.3 \mathrm{kGy}$, (c) $34.2 \mathrm{kGy}$, (d) $50 \mathrm{kGy}$, (e) $100 \mathrm{kGy}$. 


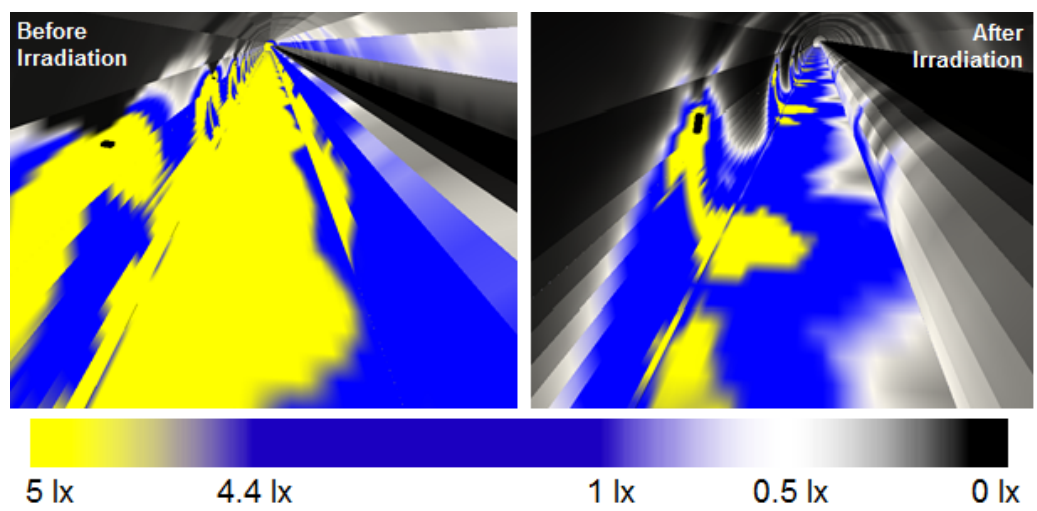

(a)

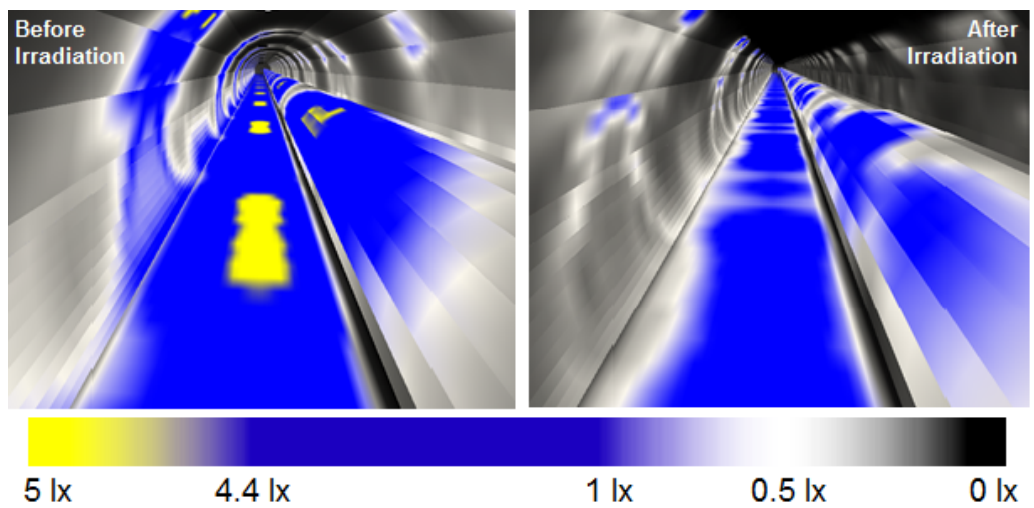

(b)
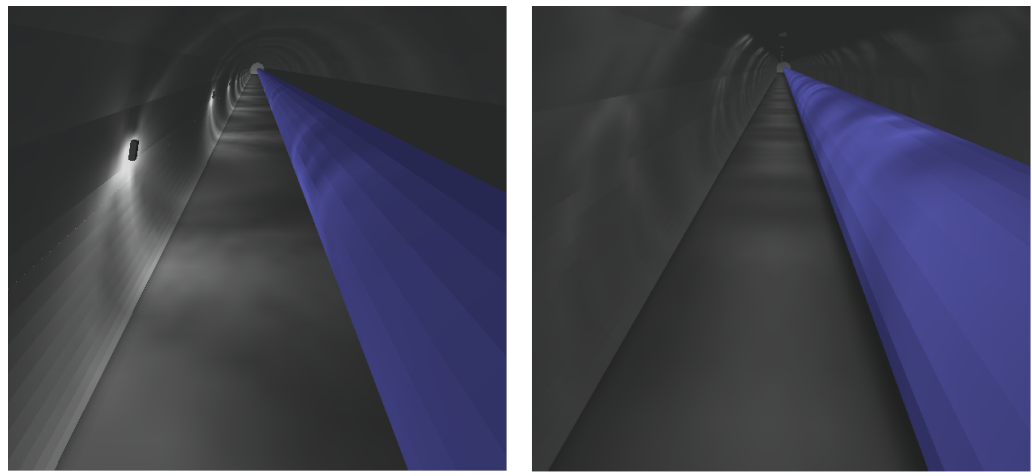

(c)

Fig. 9: (a) 3D rendering of the DIALux simulation with Vendor 1 luminaires, before (left) and after (right) $100 \mathrm{kGy}$ exposure. (b) 3D rendering of the DIALux simulation with Vendor 2 luminaires, before (left) and after (right) $100 \mathrm{kGy}$ exposure. (c) Natural visual impression using Vendor 1 (left) and Vendor 2 (right) luminaires after 100 kGy exposure.

inclusion of which allows modified COTS luminaires to remain functional up to a dose of $100 \mathrm{kGy}$. The proposed luminaires are now being installed within limited areas of the CERN accelerator complex. Future TID tests are planned in order to bound the lifetime of the whole LED luminaire; moreover, detailed study of the principal optical components, (power LEDs, plastic lenses and glass) are scheduled. Future studies identified include active and non-active irradiation tests of the reference PSU design up to $100 \mathrm{kGy}$. 


\section{Acknowledgments}

The authors would like to thank Jean-Marie Foray for commencing the LED luminaire testing programme during his time at CERN from 2009-2014.

\section{References}

[1] J. P. Saraiva and M. Brugger, "Radiation levels at CERN's injectors and their impact on electronic equipment," in Proceedings of the 11th International Topical Meeting on Nuclear Applications of Accelerators, (Bruges, Belgium), pp. 5-8, August 2013.

[2] K. Røed, M. Brugger, D. Kramer, P. Peronnard, C. Pignard, G. Spiezia, and A. Thornton, "Method for measuring mixed field radiation levels relevant for SEEs at the LHC," IEEE Transactions on Nuclear Science, vol. 59, no. 4, pp. 1040-1047, 2012.

[3] A. De Almeida, B. Santos, B. Paolo, and M. Quicheron, "Solid state lighting review-potential and challenges in Europe," Renewable and Sustainable Energy Reviews, vol. 34, pp. 30-48, 2014.

[4] J. P. De Carvalho Saraiva and M. Brugger, "Radiation Environments and their Impact at the CERN's Injector Chain,” Dec. 2015. CERN-ACC-NOTE-2015-0042, available at https://cds.cern.ch/ record/2114889.

[5] R2E, "Radiation to electronics study group (R2E) homepage," 2016. Available at http://r2e. web.cern.ch/R2E/.

[6] M. Rico-Secades, A. J. Calleja, J. Ribas, E. L. Corominas, J. M. Alonso, J. Cardesín, and J. GarcíaGarcía, "Evaluation of a low-cost permanent emergency lighting system based on high-efficiency LEDs," IEEE Transactions on Industry Applications, vol. 41, no. 5, pp. 1386-1390, 2005.

[7] P. Adell, R. Schrimpf, B. Choi, W. Holman, J. Attwood, C. Cirba, and K. Galloway, "Total-dose and single-event effects in switching DC/DC power converters," IEEE Transactions on Nuclear Science, vol. 49, no. 6, pp. 3217-3221, 2002.

[8] P. Adell and L. Z. Scheick, "Radiation effects in power systems: a review," IEEE Transactions on Nuclear Science, vol. 60, no. 3, pp. 1929-1952, 2013.

[9] A. H. Johnston, "Radiation effects in optoelectronic devices," IEEE Transactions on Nuclear Science, vol. 60, no. 3, pp. 2054-2073, 2013.

[10] J. Jimenez, M. Alvarez, R. Tamayo, J. Oter, J. Dominguez, I. Arruego, J. Sanchez-Paramo, and H. Guerrero, "Proton radiation effects in high power LEDs and IREDs for optical wireless links for intra-satellite communications (OWLS)," in IEEE Radiation Effects Data Workshop, pp. 77-84, IEEE, 2006.

[11] S. Pearton, F. Ren, E. Patrick, M. Law, and A. Y. Polyakov, "Review-ionizing radiation damage effects on GaN devices," ECS Journal of Solid State Science and Technology, vol. 5, no. 2, pp. Q35Q60, 2016.

[12] K. Toh, K. Sakasi, T. Nakamura, K. Soyama, and T. Shikama, "Effects of neutrons and gamma-rays on polymethylmethacrylate plastic optical fiber," Journal of Nuclear Materials, vol. 417, no. 1-3, pp. 814-817, 2011.

[13] A. N. Baydogan, "The effect of neutron and mixed gamma and neutron irradiation on the solar properties of borosilicate glass," Research on Chemical Intermediates, vol. 40, no. 1, pp. 299-306, 2014.

[14] D. Doyle, "Radiation hardness of optical materials," in 3rd Europa Jupiter System Mission Instrument Workshop, ESA-ESTEC, Optics Section, 2010. Available at http://sci.esa.int/ science-e/www/object/doc.cfm?fobjectid=46396.

[15] CNRAD, "Radiation Working Group (RadWG) CNRAD homepage," 2016. Available at https: //radwg.web.cern.ch/RadWG/Pages/CNRAD/cnrad_frame.htm 
[16] A. Masi, G. Spiezia, P. Peronnard, M. Donze, M. Brugger, and R. Losito, "The new generation of LHC accelerator radiation monitoring system," in Proceedings of the 18th IEEE-NPSS Real Time Conference (RT), pp. 1-7, IEEE, 2012.

[17] T. Bager, J. Casas, B. Palan, and M. Rodriguez, "Validation of switching power supplies, diode bridges, and conditioners for pressure sensors," EDMS document 1226409, CERN, 2002. Available at https://edms.cern.ch/document/1226409/1.

[18] C. C. Strabel, H. Vincke, and H. Vincke, "Radiation protection studies for the SHiP facility," Apr 2015. Available at: https://cds.cern.ch/record/2063301.

[19] J. D. Devine, "Radiation tolerant LED PSU," 2016. Available at http://www.ohwr.org/ projects/radtol-led-psu.

[20] J. Mekki, M. Brugger, R. G. Alia, A. Thornton, N. C. D. S. Mota, and S. Danzeca, "A mixed field facility at CERN for radiation test: CHARM," in Proceedings of the 15th European Conference on Radiation and Its Effects on Components and Systems (RADECS), pp. 1-4, Sept 2015.

[21] F. Ravotti, M. Glaser, and M. Moll, "Upgrade scenarios for irradiation lines: Upgrade of the Proton Irradiation Facility in the CERN PS EAST AREA," Sep 2014. Available at: http://cds.cern. ch/record/1951308. 